\title{
La identidad y el empoderamiento de las mujeres gambianas narrados a través de discursos fotográficos
}

\author{
Identity and empowerment of gambian women narrated \\ through photographic speeches.
}

\author{
Dra. M. Ileana Landeros Casillas \\ Profesora investigadora del Centro \\ Universitario de Ciencias Sociales y \\ Humanidades de la Universidad de \\ Guadalajara. México. \\ 1_ileana@hotmail.com
}

Recibido 11/10/2015

Aceptado 05/11/2015
Revisado 05/11/2015

Publicado 01/07/2016

\section{Resumen}

El artículo pretende abordar dos temas principalmente: la construcción de la identidad de las mujeres gambianas actuales y el empoderamiento que han adquirido como parte del proceso de transformación al que se les ha forzado a introducirse. Ambos temas se vinculan con la narración fotográfica como una manera novedosa de hacer uso de los estudios artísticos a la luz de la construcción identitaria y el empoderamiento colectivo como base de proyectos económicos, políticos y socioculturales nacidos

\section{Abstract}

The article intends to explore two topics in particular: the identity construction of current Gambian women and the empowerment that they have acquired as part of the transformation process that has forced them to enter by themselves. Both topics are linked with the photographic narration as a novel way of using art studies by the construction of identity and collective empowerment as the basis of economic, political and cultural projects

\section{Para citar este artículo}

Landeros Casillas, M. I. (2016). La identidad y el empoderamiento de las mujeres gambianas narrados a través de discursos fotográficos. Tercio Creciente, 10, págs. 7-24. http://dx.doi.org/10.17561/rtc.n10.1 
desde las necesidades de esas mujeres. El discurso que se analiza en este texto es creado desde la horizontalidad de la metodología Entre Voces, tomando en cuenta los estudios subalternos, la perspectiva de género, los discursos feministas y la educación artística. born from the needs of these women. The speech is analyzed in this paper is created from the horizontality of the methodology Between Voices, considering subaltern studies, gender, feminist discourses and art education.

Palabras clave / Keywords

Mujeres, empoderamiento, identidad y fotografía.

Women, empowerment, identity and photography.

\section{Para citar este artículo}

Landeros Casillas, M. I. (2016). La identidad y el empoderamiento de las mujeres gambianas narrados a través de discursos fotográficos. Tercio Creciente, 10, págs. 7-24.

10.17561/rtc.n10.1 


\section{La identidad y el empoderamiento de las mujeres gambianas narrados a través de discursos fotográficos.}

\section{Introducción}

Este artículo es el resultado de un año de trabajo (2013-2014) realizado en la comunidad de Lamin, en Gambia, con las madres de familia de algunos estudiantes de la escuela Canarias- Lamin Nursey School cuyo objetivo fue sentar las bases de la red de mujeres trabajadoras de Lamin, a través de un programa de educación artística donde la fotografía permitiera a las mujeres visualizar y valorar sus tradiciones y replantear proyectos en común, nacidos desde las necesidades de la comunidad para posibles Organizaciones no gubernamentales (Ongs) que deseen colaborar en esa comunidad.

Para hablar de las mujeres gambianas en el mundo contemporáneo es necesario comprender su actuar, entendiendo primero el contexto general al que pertenecen. Para ello debemos tener en cuenta los efectos y transformaciones que el contacto con la civilización occidental causó sobre la civilización africana. Esta circunstancia ha dejado una huella que ha convertido a la mujer, como a muchos de los aspectos de aquel continente, en el resultado de una cultura tradicional y otra ajena a ésta que se sobrepuso durante los siglos más recientes de la historia, y que además, descolonizó
África negra a una velocidad vertiginosa a partir de la década de los sesenta del siglo XX (Algora, 2003).

Es más que evidente que la presencia europea transformó por completo la vida africana. Las estructuras y relaciones sociales, las creencias y costumbres y el sistema económico. Deshicieron los imperios y sometieron a los dirigentes autóctonos, que aunque se resistieron acabaron claudicando ante la acción de los europeos. De esta forma se fracturó el equilibrio cultural y material existente, siendo sustituido por una relación de dependencia generada por la instalación del sistema capitalista. El capitalismo, integrado en una economía y comercio mundial, explotó los recursos de África y obligó a los pueblos a trabajar, no para sí mismos (como en antaño), sino para el desarrollo europeo (Jabardo, 2005).

Bajo este panorama, la mujer africana en general y la gambiana en particular se vio en la necesidad de reinventarse y encontrar su lugar en este amalgama de situaciones, pues si bien, el lugar, la jerarquía y las actividades de las mujeres se vieron afectadas y por 
consecuencia la evolución de sus sistemas de producción, comercialización, interacción, etc., también afectó las costumbres sociales que regían el trabajo por sexo y grupos de edad.

Actualmente en Gambia es más marcado en las zonas rurales la división del trabajo por sexo, grupo de edad y tribu, características de la sociedad tradicional. En los pueblos de subsistencia agrícola, las actividades del campo y la producción de alimentos normalmente estaban reservadas para la mujer, las cuales también se encargan de las actividades domésticas, incluyendo la recolección de leña y el acarreo del agua. A los hombres se les solía reservar el pastoreo, la caza y la guerra (Algora, 2003). Sin embargo, día a día son más las mujeres que hacen un lado las creencias tradicionales y realizan trabajos que las sitúan en posiciones de empoderamiento, cuyo único objetivo es: subsistir, alimentar a sus familias y tener un futuro mejor.

Este trabajo pretende reconocer, conocer y utilizar el lenguaje creativo dominante de nuestra época, el lenguaje audiovisual, como una herramienta necesaria para cualquier persona que desee comprender la realidad en la que se encuentra sumergida. Para este caso utilizamos los discursos fotográficos a través de un taller de fotografía que se impartió como una de las primeras actividades que se realizaron durante la creación de la red de mujeres trabajadoras. Nos basamos en la idea de que la influencia de la sociedad sobre el rango y ejercicio de las decisiones también significa empoderamiento, por lo que para este trabajo, debemos al mismo tiempo considerar los factores que afectan el estatus y derechos de las mujeres como grupo.
Por ello, cuando se comenzó a trabajar con las madres de familia de Lamin, se pensó en hacer una actividad artística, ya que el arte es algo que ellas reconocen y está presente dentro de su cultura. Hacer uso de la fotografía para visualizarse como mujeres activas y reconocerse a través de imágenes, fue un acierto, pues normalmente la cámara y las fotografías son herramienta que solo reconocen en manos de los extranjeros; hacer uso de esos recursos les otorgó el poder de decidir sobre su persona, imagen y entorno. No es lo mismo verse diariamente ante un espejo, recorrer tu comunidad bajo los ojos de la cotidianidad, que construir visualmente la identidad frente a una cámara y proyectar entonces la imagen que quieres que el resto del mundo reconozca sobre ti, de manera individual y colectiva.

Trabajar colectivamente con este grupo de mujeres fue en principio reconocerlas como parte importante de la sociedad, ya que para ellas los logros de las mujeres en lo individual genera impacto en la manera en que la mujer es percibida y tratada en su comunidad, pero hay que poner atención al empoderamiento individual que la mujer adquiere, porque usualmente es limitado, y si ella no tiene un grupo con el que se identifique y la apoye entonces generalmente son desempoderadas. Por tal razón, como la misma Seera Manneh, la dama de la sociedad como cariñosamente le llaman, expresó en una de las primeras reuniones: "todas estamos en la misma rapa, si la rapa se rasga, no solo cae una, caemos todas".

\section{Gambia y la comunidad de Lamin}

La región en donde se desarrolla este estudio es en Gambia, una nación cuyos únicos 
límites son Senegal y el océano Atlántico. Habitan 1.7 millones de personas aproximadamente, y se caracteriza por un flujo constante de nacionalidades y culturas, es decir, por la interculturalidad de razas y tribus que conviven pacíficamente. Según datos del Gobierno Gambiano destacan cuatro tribus principalmente: mandinkas, wolof, jolas y fulas. La lengua oficial es el inglés.

Las ciudades son prácticamente inexistentes, aunque hay siete enclaves de más de 10 mil habitantes: Banjul, Bakau, Basse Santa Su, Brikama, Karafenni, Kaniffing, Serrekunda y Yudum. Como en muchos países africanos en Gambia también las estructuras sociales están basadas en la vida comunitaria, que sigue siendo muy importante en los poblados, ya que después de la pertenencia a la familia, es el arraigo a la aldea el que da sentimiento de fortaleza y protección.

Gambia es un país mayoritariamente musulmán; aproximadamente el 92 por ciento de su población la profesa, de tal manera que al ser musulmanes los hombres pueden tomar hasta cuatro esposas, sin embargo, sus mujeres no se parecen en nada a las de países islámicos donde las mujeres apenas participan en la vida pública y solo salen de sus casas vestidas de negro. Por el contrario, las mujeres gambianas están por todas partes. Suelen ir alegremente vestidas, con bonitos trajes de colores brillantes y estampados, con cortes ceñidos que realzan sus cuerpos femeninos y seductores. Enseñan sus brazos y lucen escotes sin ningún problema. Saben llamar la atención, se las ve decididas y enérgicas, se ocupan de la familia y, a menudo, también trabajan fuera de casa o tienen pequeños puestos en donde vender alguna mercancía.
Las mujeres normalmente viven con sus padres hasta que se casan, momento en el que pasan a formar parte de la familia del marido. Lo normal es que los miembros de una familia bajo el mismo techo sean muy numerosos y que convivan abuelos, padres e hijos. Las tasas de alfabetización en Gambia son muy bajas, en torno al 40 \%, pero en las mujeres están 10 puntos por debajo.

Lamin es una pequeña comunidad mandinka, que se encuentra a 10 kilómetros del aeropuerto, con 25 mil habitantes aproximadamente, de los cuales el 40 por ciento son niños y niñas. Esta comunidad sobrevive gracias a la agricultura y a la pesca principalmente, el resto de los oficios que destacan es la comercialización de productos varios, la confección de ropa y la construcción.

\section{Abordaje teórico- metodológico.}

Actualmente es difícil que en las comunidades, por más lejanas que se encuentren, no introduzcan nuevos conocimientos que atenten contra su autenticidad. Es muy difícil que una comunidad se mantenga al margen de todos los avances tecnológicos de una cultura global, y que estos no repercutan de una u otra manera en su imaginario y por consiguiente eso provoque cambios que enriquezcan o eliminen su identidad. En nuestros tiempos y con la ayuda de las tecnologías, los medios de comunicación y las redes sociales, los cambios de la cultura se producen bajo distintas gamas de tonalidades en donde la transculturación se identifica como el fenómeno social intermedio que ocurre cuando un grupo social recibe y adopta las formas culturales que provienen de otro grupo. La sociedad, por lo tanto, termina sustituyendo en mayor 
o menor medida sus propias prácticas culturales (Herrero, 2002).

En todo el mundo conviven enfoques inclusivos que apoyan concepciones postmodernas sobre teorías de interpretación en donde los medios de comunicación fungen como herramientas, por lo que se corre el riesgo de ofrecer una visión limitada o parcial, o bien centrarse en algunos aspectos puntuales como la interpretación de significados sobre imágenes, algunas veces contrario al que actor social ve o interpreta, limitando así la participación de aquellos que realmente pueden y quieren comunicar algo a través de sus imágenes. Creemos entonces que la Educación Artística tiene que dar valor a aquello que distingue las artes. Las artes visuales hacen visibles aspectos del mundo (como sus cualidades expresivas) a través de vías que otras formas de visión no hacen (Marín, 2000).

Para esta investigación utilizamos el término de transculturación como el término que nos permite unir la cultura fotográfica, tan extendida y usada en occidente, para insertarla dialógicamente en un contexto cuyos rasgos identitarios no van acorde al crecimiento y desarrollo de las nuevas tecnologías como sucede en algunas entidades. En este sentido, no intentamos que las costumbres de algunos pueblos sean modificadas o adquieran otro significado, sino más bien valernos de una tecnología conocida, que está presente en la comunidad, pero no con la frecuencia y facilidad con la que es utilizada en otras culturas.

Reconocer la identidad de la mujer africana visualmente es entender otra forma de asimilar la realidad, que a diferencia de otras formas de transmitir conocimientos, ésta se basa en la construcción de imágenes fotográficas, en diálogos visuales, en construir una realidad Entre Voces, desde la horizontalidad, entreculturalmente, entre no inter, porque desde la perspectiva de los estudios culturales la interculturalidad se define como la interacción respetuosa entre diferentes culturas que conviven en un mismos espacio social en donde el punto de vista del investigador, por muy apegado que sea a la realidad, es el único que se escucha. Entreculturalidad en cambio, nos permite entresacar, entrever, entretejer desde los diálogos construidos por todos, donde la voz del investigador es una más que se suma a las voces, miradas y sentires que unidas construyen una sola realidad (Corona, 2007).

Bajo esta perspectiva entendemos que la sociedad es un conjunto de individuos que viven bajo unas mismas normas, leyes y cierto protocolo, tienen sus subculturas y subgrupos y la mayoría de los individuos de la sociedad se dirigen hacia un fin común, es así, como en el interior de las sociedades del mundo se van construyendo conceptos más profundos que definen ciertos rasgos como la identidad colectiva, y que tiene que ver con el estado de conciencia implícitamente compartido entre los individuos que reconocen y expresan su pertenencia a una categoría de personas de la comunidad que los acoge.

Marcela Largarde explica cómo la identidad de las mujeres africanas se ha ido construyendo: "las personas sometidas a formas particulares de explotación, opresión y marginación quienes, al recrear sus historias e identidades propias, realizan la crítica a la modernidad y a su más valiosa 
promesa: el desarrollo" (Lagarde, 1999: 6). Ante tal situación, la cultura feminista ha defendido por más de dos siglos una nueva visión del mundo en una propuesta holística que se fundamente en una etnicidad que reclama la aceptación basada en el reconocimiento de la equivalencia humana, y las mujeres gambianas son el más vivo ejemplo que demuestran el hecho de que no hay desarrollo humano sin las mujeres, y que la democracia, indica en primer término, la democracia genérica.

El simple hecho de ser africana y mujer las coloca automáticamente en el segmento de estudio académico de la "otredad", y para ello hay un sinfín de enfoques desde donde podemos construir los discursos de las mujeres africanas, desde donde analizar sus diálogos, voces, narraciones, en todo caso tomamos en cuenta los estudios subalternos como aquellos estudios que reconocen el estudio de las sociedades poscoloniales a partir de una narrativa histórica que reconoce a la "gente común", "las masas", "los olvidados" como auténticos catalizadores del devenir histórico. Por ser estos una alternativa para leer las historias de las sociedades "desde abajo" (Lagarde, 1999).

Sin embargo, sería ingenuo y contradictorio de mi parte contar las historias de las mujeres gambianas desde el punto de vista subalterno, intentando hablar por ellas, por ello sustento $\mathrm{mi}$ investigación en la metodología Entre Voces, para intentar describir la realidad de estas mujeres, pero desde su propia voz, sin opacar la mía, ya que mi experiencia con ellas por cuatro año, nos permitió formar un vínculo con el que me identifiqué como madre, mujer, amiga, maestra y asesora, y en donde mis raíces mexicanas además, me permitieron colocarme también en la otredad, pero en un contexto diferente, que a lo largo de este trabajo permea o se lee entre líneas intentando no perder jamás la horizontalidad.

"Los retos de las mujeres en el mundo y las luchas por sus derechos se enfocan, a menudo, desde el punto de partida del cuestionamiento del sistema de género y de los arquetipos de feminidad que imponen los patrones culturales predominantes" (Nash, 2004: 27), para el caso de Gambia pareciera que los ecos impuesto por la colonia británica brotan y se esconden, y a menudo hay que agudizar la vista para entender de dónde viene tal o cual cosa.

Como he dicho anteriormente es necesario profundizar en el contexto gambiano porque África entera es un continente lleno de matices que hay que tomar en cuenta, ya que la situación de la mujer varía en cada una de las sociedades africanas, y es por eso que debemos ahondar en las especificaciones que se construyen en las narraciones visuales de estas mujeres, pues solo a través de dichos discursos nos revelarán las circunstancias (económicas, políticas, sociales, legales, etc.) que contribuyen a facilitar la capacidad de actuación dentro de su sociedad.

Las mujeres gambianas no huyen, no se excluyen o no se asumen como "subalternas". Desde sus diferentes concepciones ellas aceptan y asimilan las diferencias que por tradición, imposición o simplemente porque les tocó vivir se asumen diferentes y son capaces de identificar sus diferencias con sus pares más cercanos: las europeas. Es común que algunos estudios de mujeres africanas, tomen en cuenta las discusiones de género o 
las feminidades para reconstruir la historia de esas comunidades porque también ahí se vive división sexual de trabajo en donde la mujer es solo un soporte masculino y no el soporte económico, emocional, familiar y comunitario que actualmente tiene, por lo menos en el Gambia actual.

Muchos estudios describen las realidades africanas como un todo homogéneo desde la inercia de la voz de unas cuantas africanas quienes intervenir en foros o conferencias, pero que por situaciones económicas principalmente son minoría. Esto no significa que no haya historias que contar, al contrario, hay muchas que no por pertenecer al subalterno carecen de validez. "Las mujeres como cualquier otro grupo subalterno, son agentes potenciales de cambio y transformación social, con la capacidad de impulsar y movilizar" (Aguilar, 2013:662).

Para este estudio fue importante reconstruir la identidad de las mujeres gambianas a través de imágenes, por el significado que otorgan los elementos, poses y contextos que intervienen en una composición fotográfica, además de que al cruzarlos con sus discursos verbales nos proporcionan una visión más clara y precisa de cómo se visualizan en el espacio público, ya que hay quien dice que para entender la postura de estas mujeres es necesario adentrarse en las diversas interacciones que han sufrido a lo largo de la historia, hablamos de interacciones, de dominio y sumisión, intersecciones y fusiones entre las tradiciones propias de las tribus africanas y las coloniales como movimientos feministas o de mujeres, según afirma la socióloga Oyewùmí, durante la Primera Conferencia de Mujeres Africanas (2012).
Sin embargo, siguiendo a Oyewùmí (2012) es necesario cuestionar primero el uso del género como principio de organización social en la sociedad africana, ya que a menudo se confunden diversos y complejos roles femeninos bajo un único prisma. Por ejemplo, "las mujeres Yoruba precoloniales participaban de muchos roles superpuestos e incluso paradójicos, tales como marido, esposa, madre, cuñada, hijo/a (en muchas lenguas africanas un término neutro), comerciante, cultivadora, etc". Y resalta que conceptos, tales como mujer/ mujeres, cuando son tomados fuera de su contexto etnográfico e histórico confunden, más que clarifican.

Desde esta perspectiva y en el contexto africano, las concepciones de género resultan mucho más complejas: por ejemplo, no se puede equiparar ser esposa con ser madre, dice Oyewùmí (2012). Lo más significativo de todo esto, es reconocer que el género, no es una categoría necesariamente estática ni fija, ni definida como opuesta a otro género (el masculino), sino que está en verdad construida socio culturalmente y que, además, evoluciona en sus significados y contenidos con el tiempo; para cada mujer puede fácilmente modificarse durante su ciclo de vida o ser muy diferente para las mujeres de distintos contextos históricos, sociales y políticos.

El proceso de empoderamiento se vincula entonces a los cambios en la identidad, en la forma de percibirse a sí mismas y desde ese lugar, percibir a las (los) otros; es un proceso que implica dolor, sufrimiento, porque se mueven estructuras, en el sentido de que lo que parecía incuestionable, ahora lo es, y no sólo eso, sino las protagonistas encuentran la posibilidad de cambiarlo. En el caso de las mujeres de Lamin, ellas ya conocían el sabor 
del empoderamiento, pues fueron ellas quienes fundaron la escuela Canarias Lamin Nursey School; un proyecto quizá un tanto rudimentario que en aquel entonces alrededor del año 2000, según me contaron, se creó a manera de guardería lo que ahora es la escuela antes mencionada, y por turnos se apoyaban unas a otras en el cuidado de los hijos para que así todas pudieran trabajar.

Paralelamente, esas mujeres hartas de no tener que comer, invadieron tierras que estaban aparentemente abandonadas y empezaron a sembrarlas; no tardó mucho tiempo para que el dueño de las tierras las echara y destruyera sus sembradíos. Eso no impidió que ellas nuevamente se metieran y sembraran otra vez; nuevamente las volvieron a echar y paulatinamente fue en aumento la violencia. Hasta que se movilizaron y el asunto llegó a oídos del presidente de Gambia, Yahya Jammeh, quien después de meses de negociaciones giró instrucciones para que las tierras pasaran a ser de las mujeres de Lamin. El ejemplo se ha extendido a otras comunidades de Gambia.

Con el ejemplo anterior entendemos que el empoderamiento se da a nivel cognitivo en primera instancia, es un proceso donde las mujeres hallan tiempo, espacios propios y empiezan a reexaminar sus vidas en forma crítica y colectiva (Batliwala, 1994). Kabeer (1998) lo define como la expansión de la habilidad de las mujeres para hacer elecciones estratégicas de vida en un contexto donde previamente les estaba negado. Asimismo, el empoderamiento incluye tres niveles: el nivel personal, que implica desarrollar cambios en la forma en que la persona se autopercibe, se da mayor confianza individual y se generan diversas capacidades, $y$, un aspecto importante consiste el liberarse de la opresión internalizada. El segundo nivel que tiene que ver con desarrollar habilidades para negociar e influenciar las relaciones de poder y la toma de decisiones en el interior de estas relaciones, y el tercer nivel en donde el empoderamiento colectivo que implica el trabajar en objetivos comunes, y con ello tener un impacto más amplio que trasciende el poder que cada individuo puede desarrollar (Martínez, 2000).

\section{El discurso fotográfico de las gambianas}

La herramienta principal de esta investigación como se mencionó desde el principio se basó en enfocar una rama de la Educación Artística como instrumento para promover la comprensión de la cultura visual, es decir, ayudar a las mujeres a aprender a descodificar los valores y las ideas que encontramos en lo que llamamos cultura visual. Leer las imágenes como textos para revelar su política y sus propósitos ocultos es una forma de lectura. Otra es desarrollar la habilidad para usar las artes comprendiendo sus valores y las condiciones de vida de los que viven en una sociedad multicultural (Juanola \& Calbó, 2004).

La impartición de un taller fotográfico a través del cual se vertieron una serie de conocimientos teóricos y prácticos, además de una retroalimentación de la información como trasfondo de este proyecto, fue el instrumento a través del cual hilvanamos las palabras con las imágenes lo que coadyuvó al esclarecimiento de las ideas. Basamos gran parte de este taller en la experiencia de Wendy Ewalds (1969-1999), quien ha trabajado desde hace más de 30 años en 
talleres de este tipo en más de 20 sitios alrededor de todo el mundo.

Además la experiencia de la doctora Corona Berkin (1988 a la fecha) en sus estudios de la sierra huichol nos permiten apreciar cómo los procesos de apropiación de ideas contextualizadas y narraciones verbales y fotográficas, han ayudado a estudiantes wixarikas de secundaria a entender su realidad y sostener así sus imaginarios y realidades alternas permitiéndoles defender sus raíces no por el simple hecho de existir, sino porque a través de sus vivencias han entendido la diferencia entre ellos y nosotros.

Bajo este contexto se pensó en profundizar en ejes temáticos a lo largo de todo un año (más abajo se detallan), ya que el taller se impartió durante todo un año, aunque mi relación y proyectos con las mujeres me vinculó por espacio de cuatro años. Las clases se impartieron dos veces por semana, dos horas en la tarde y dos horas sábados o domingo. En este estudio participaron 21 mujeres, de las cuales 18 eran mujeres nacidas y arraigadas en la comunidad Lamin, y 3 fueron maestras de la escuela que decidieron participar voluntariamente. Las sesiones teóricas se realizaron en las instalaciones de la escuela, y las prácticas se buscaron locaciones en donde las mujeres estuvieran de acuerdo. La introducción de los ejes temáticos fue un acompañamiento paulatino no solo en la maduración de los procesos propios de la fotografía, sino también, como una manera de acompañarlas en la construcción de sus discursos narrativos, por lo que los resultados finales (que más adelante se describen) son reflejo de una maduración en su posicionamiento como mujer, en donde de forma acertada vinculan las palabras con las imágenes, además del conjunto de elementos que introdujeron para crear un mensaje visual.

El taller de fotografía se rigió bajo tres ejes fundamentales, Cómo quiero ser reconocida; Mis tradiciones y Mis sueños con el objetivo de que este abordaje fuera una reflexión interna que les replanteara una concepción acerca de lo que ellas esperan de sus vidas. Todos los temas que a continuación se describen se trabajaron por parejas, ya que en todas las composiciones las mujeres quisieron aparecer en las fotografías.

Cómo quiero ser reconocida: en este apartado las mujeres tenían que construir su propia imagen cómo deseaban ser reconocidas o vistas en el espacio público, qué poner o qué dejar dentro de la imagen para complementar. Fue durante estas sesiones en donde se introdujeron de manera general las reglas básicas de la fotografía, la regla de tercios, cómo, cuándo y qué enfocar, el posicionamiento de la luz, etc.

Mis tradiciones: sobre este tema las mujeres debían hacer una reflexión sobre lo que significan sus tradiciones, y hacer una imagen que demostrara el arraigo a sus raíces, aquellos que quieren que sus hijos y nietos sigan conservando, aquello de lo que se sienten orgullosas. En general debían proyectar la visión que les da su entorno, cuáles son esos espacios, lugares, experiencias, relaciones, nostalgias, acciones, etc. que reconocen en la construcción del espacio desde su casa, familia y comunidad, y lo vincularan con sus sentires, intentando imprimir en cada imagen los rasgos identitarios de su persona y su entorno. 
Mis sueños: en esta sesión las mujeres tenían mucho más conocimiento de los recursos fotográficos, por lo que tenían la libertad de apoyarse con varias imágenes en la redacción fotográfica con planos generales y a detalle. La práctica buscó que fueran capaces de externar desde su perspectiva el conocimiento de su entorno, sus propuestas, oficios, necesidades, injusticias, etc. y opinar, demandar, o dar a conocer al mundo cuáles son sus aspiraciones, cómo se proyectan en un futuro y hasta dónde son capaces de llegar. El ejercicio fue un rico recorrido de sentires, conocimientos y realidades ligada a una propuestas de cambio.

\section{Resultados}

Llevar a cabo un taller fotográfico como una de las primeras actividades que se realizaron durante la creación de la red de mujeres trabajadoras de Gambia, fue sin duda un gran acierto, pues esto permitió estrechar las relaciones entre ellas, intercambiar puntos de vista sobre sus orígenes y sus planes a futuro. A través del taller pudieron replantearse sus sentires, ambiciones, visiones del mundo, hacer una reflexión sobre sus relaciones, roles, saberes, deberes y debilidades que les permitió redefinirse y reconocer cuáles son sus capacidades.

La visión actual sobre la mujer africana (Berger, 2003) está cuestionando construcciones socioculturales estáticas y universales del género. Igualmente, está poniendo de manifiesto toda esa complejidad y diversidad de roles de género que influyen en la sexualidad, la maternidad, las formas femeninas de asociación y organización, las conexiones entre políticas nacionales y movimientos sociales y políticos de mujeres; se está removiendo con la finalidad de saber dónde, cómo y por qué accedemos o no las mujeres a determinados ámbitos de poder.

Lo anterior se hace presente en las composiciones fotográficas que hacen las mujeres. La práctica arrojó poco más de 600 fotografías, algunas de las cuales se clasificaron como temas libres y poco más de 400 fueron tomadas en cuenta en las categorizaciones que más abajo se explican. Todos los temas fueron abordados por parejas y las mujeres eran libres de buscar las locaciones que mejor se ajustaran a sus ideas, o bien llevarse las cámaras fotográficas a sus casas. Las cámaras que se utilizaron fueron 6 cámaras digitales Nikon de 8 mega píxeles.

Acerca del primer tema Cómo quiero ser reconocida, se dispararon poco más de 145 fotografías, en ellas se retrata su presencia en la cotidianidad, es decir, la mayoría de las mujeres decidieron aparecer haciendo labores cotidianas como lavando ropa, preparando comida, barriendo, sembrando, o cargando en su cabeza una hilera con bebidas caceras y en la espalda su hijo atado con una rapa. Los discursos en general que las mujeres dieron acerca de las poses que utilizaron fueron que ellas deseaban ser reconocidas como mujeres trabajadoras, fuertes, madres de familia, emprendedoras y capaces de sacar adelante cualquier proyecto que ellas tengan en mente.

Sin embargo, una de las fotos que más llamó mi atención fue la de Hina Saho de 50 años, ella es cocinera desde hace 5 años en la escuela Canarias Lamin Nursey Schooll, y ella para esta sesión decidió posar sentada en la escuela, afuera de un salón, con una 
libreta en su regazo y un lápiz en su mano. Al preguntarle por qué decidió posar así, respondió: "yo quiero ser reconocida como una mujer, madre y abuela que estoy aprendiendo, y que la edad para mí no es una limitante".

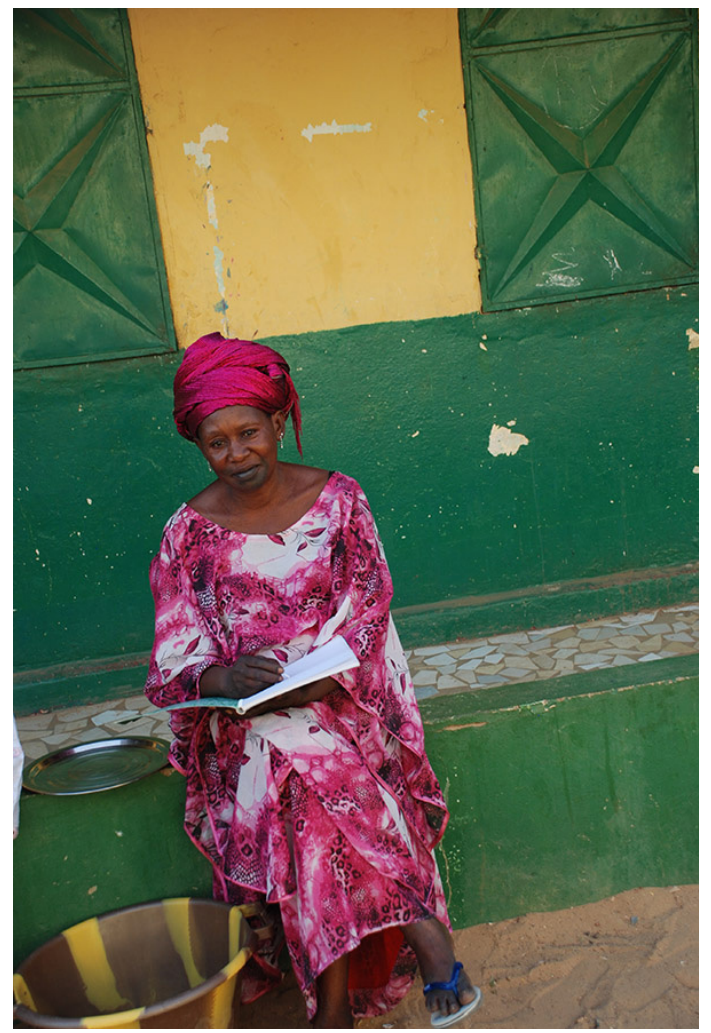

F1. Estoy aprendiendo. Lamin, 2014. Fotografía de Mariama Gomez (C) ICP.

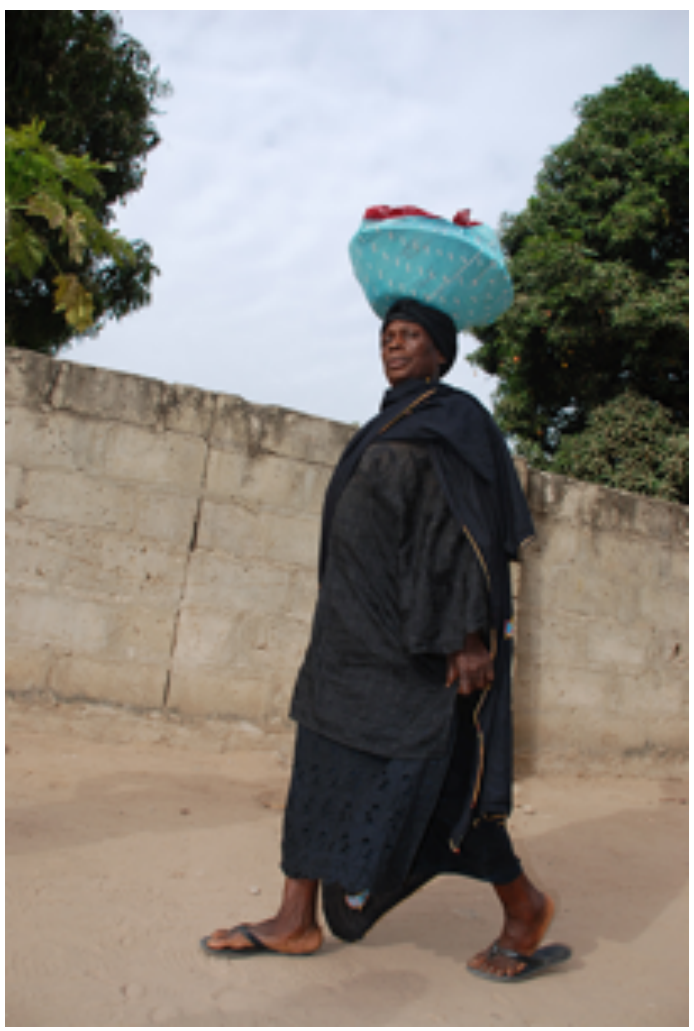

F2. Sammeh va al Río, 2014. Fotografía de Jainana Jatta (C) ICP.

El segundo tema, Mis tradiciones reunió alrededor de 115 fotografías en las cuales las mujeres fueron capaces de plasmar toda clase de tradiciones, desde juegos tradicionales, hasta la forma animada en la que ellas siembran el arroz, cómo bailan, cómo se ponen el manto en sus cabezas, cómo cosechan. Las imágenes son el reflejo de que la mujer africana es pura energía, son el motor silencio que da vida a su

comunidad. Sus actuares cotidianos son el mejor ejemplo de cómo heredan la tradición, que forma parte de su identidad, a sus hijos.

A las fotografías les faltó narrar, una parte que no se ve. Normalmente el taller se impartía a las cuatro de la tarde, pero después de algunas semanas me percaté 
que el tiempo no transcurre ni se rige a través del reloj como en occidente, ellas veían el cielo y calculaban el tiempo, o terminaban sus labores y entonces se presentaban al taller con más de una hora de retraso. La experiencia de vivir entre ellas, ver la fatiga y el cansancio en sus caras, me permitió entender que a pesar de estar exhaustas y sudorosas de trabajar en la tierra, de lavar, o de cualquier cosa que ellas estuvieran haciendo, siempre estaban dispuestas a aprender con una sonrisa en la cara, a contarnos cómo es su vida, cómo se aferran a sus tradiciones, porque finalmente esa es su esencia, es así con alegría cómo aceptan sus roles y cómo se reinventan o se acoplan a las modernidades que les va dictando la vida.

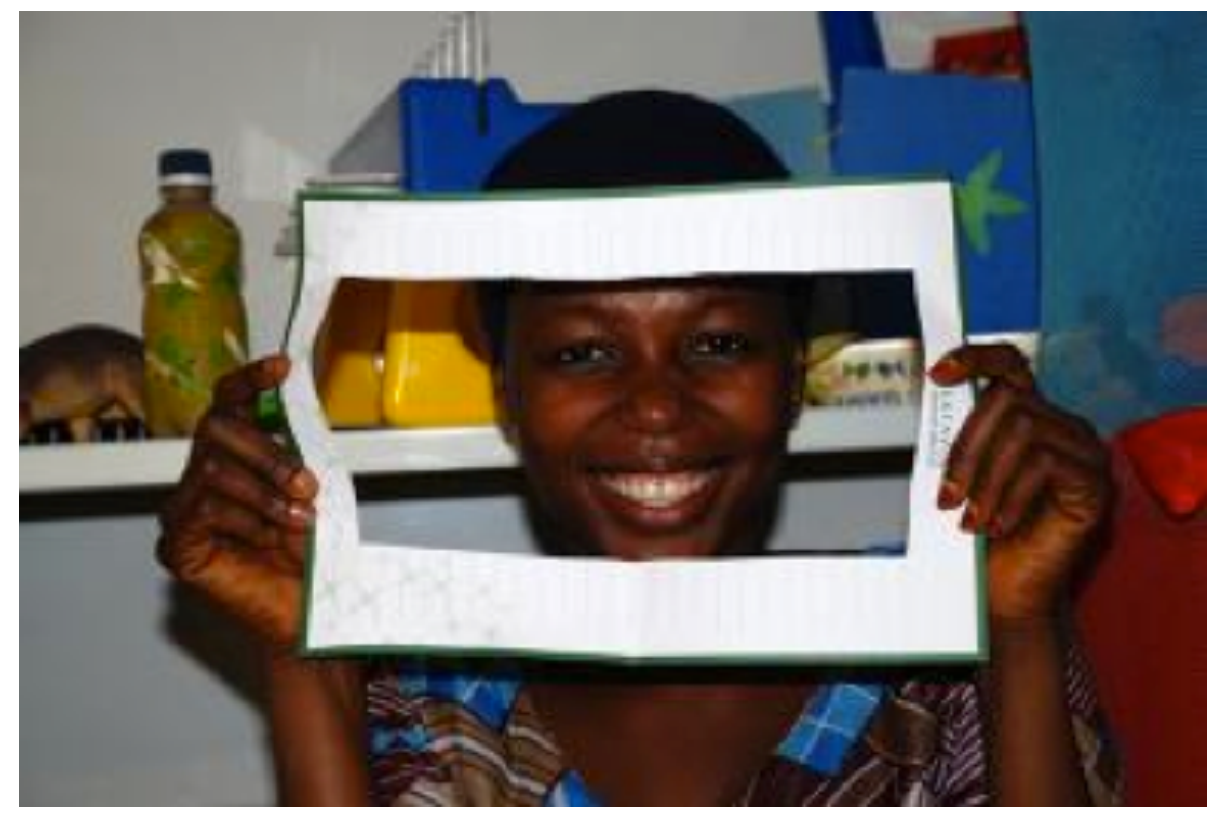

F3. Francess en clase de Fotografía. Lamin, 2014. Fotografía de Sofi Sambou (c) ICP.

Finalmente el tercer tema Mis sueños, las mujeres hilvanaron sus sueños con aproximadamente 155 fotografías. La narración fotográfica que nos muestran, nos expone no solo lo que son capaces de hacer, sino también en este apartado afloraron sus miedos más arraigados, ya que todas hicieron tomas apegándose literalmente al significado de la palabra sueños.
En este apartado las señoras se retratan soñando que una víbora las perseguía, o que estaban a punto de quemarse, que el Kong kuran (personaje que espanta los malos espíritus) las alcanzaba, se sueñan alcanzando mangos y comiéndoselos, o jugando con sus hijos. Se sueñan de mil maneras, pero sus proyecciones... sus 
sueños a futuro en todos los casos, se refirieron a los deseos de darles un presente mejor a sus hijos que el que ellas tuvieron, se sueñan con sus hijos terminando la escuela y obteniendo un buen trabajo fuera de Gambia desde donde les manden dinero, o que son sus hijos les compran una campao (casa) propia con muchas habitaciones.

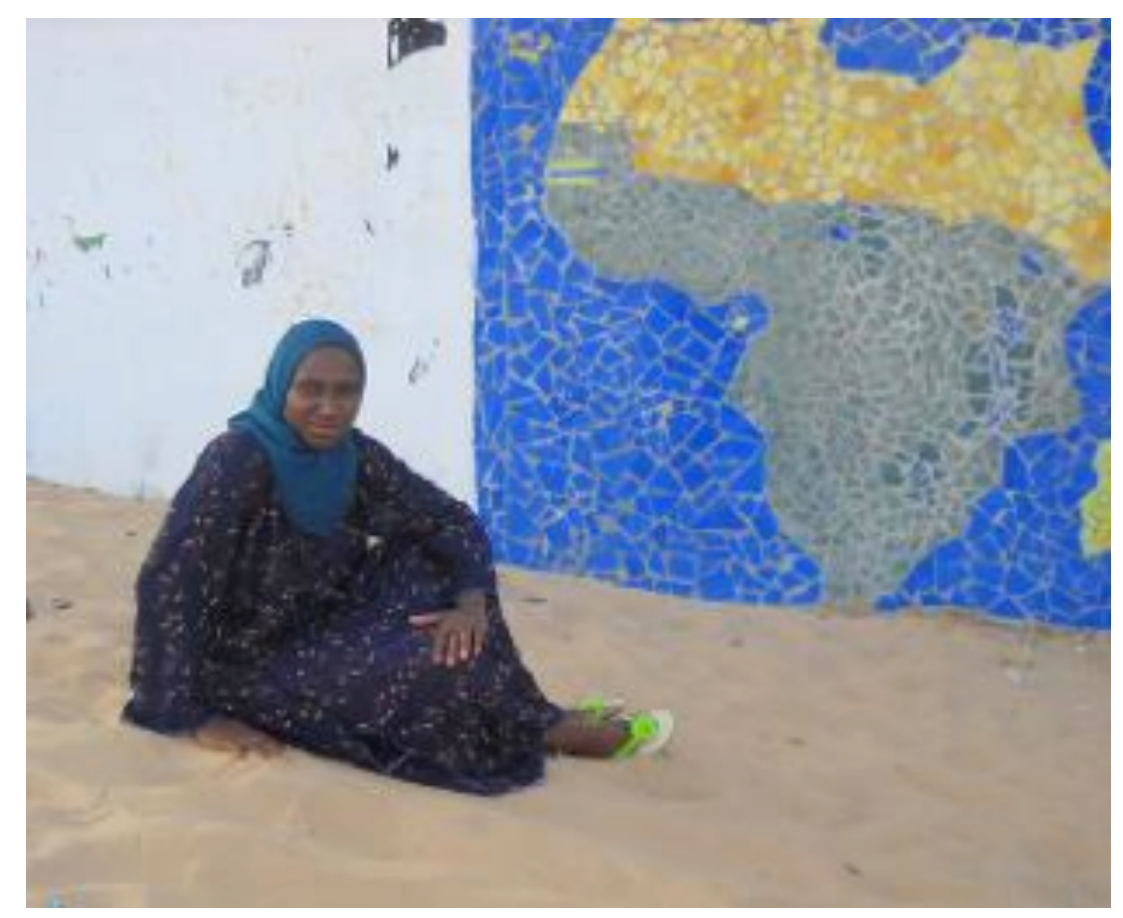

F4. Nene y Gambia. Lamin, 2014. Fotografía de Francess Manga (C) ICP.

La narración de fotografías de estas mujeres, son muestra del lado sensible y fuerte de las gambianas y de muchas mujeres en el mundo, en donde la pobreza, la falta de servicios de salud, las limitaciones de todo tipo, las lleva a adaptarse a las circunstancias, a ser creativas para hacer su vida más llevadera con el único objetivo de heredarles un futuro mejor a sus hijos. Son muestra de cómo afrontan con entusiasmo lo que les tocó vivir, sobre todo porque en este segmento de población sus problemas, dificultades o sobresaltos tienen que ver con la economía y la salud. Esta comunidad concretamente retrata su manera de sobrevivir y sobrellevar una vida digna en un contexto difícil.

\section{Conclusiones}

Las mujeres que han sido excluidas de la toma de decisiones casi toda sus vidas con frecuencia carecen del sentido que les permite definir metas y actuar efectivamente para lograrlas. Pero estas metas también pueden ser fuertemente influenciadas por los valores de la sociedad en la cual viven, por lo que en 
ocasiones pueden replicar, en lugar de desafiar, las estructuras de injusticia. El peso de la socialización lo expresa elocuentemente una mujer activista de Prishtina, Kosovo: Hay educación en la familia: primero, no debes hablar porque eres una mujer, luego más adelante no debes hablar porque nadie se va a casar contigo, más tarde no debes hablar porque eres una recién casada. Finalmente, tal vez tengas la oportunidad de hablar, pero no lo haces porque te has olvidado de cómo hacerlo.

Intentar desdibujar un panorama africano es por demás difícil y contradictorio, pues si bien el estudio intenta ser lo más objetivo posible, sin embargo existen algunas contradicciones en la sociedad gambiana, que no entendía hasta que terminé el estudio, como por ejemplo, si ellas son capaces de emprender cualquier cosa que se propongan cómo no son capaces de promover que llegue agua o luz a su campao, o acercarse una bombona de gas y una estufa para cocinar más cómodamente. Me queda claro que son reflexiones en donde antepongo la experiencia social occidental en la que crecí, y es evidente que ellas no necesitan facilitarse la vida, sus prioridades son otras.

No obstante y a pesar de estas situaciones y apreciaciones, en Gambia las mujeres están promocionando cambios positivos por medio de asociaciones de mujeres; las mejoras vendrán a través de su participación en espacios de toma de decisiones y de poder. Mientras tanto para ellas es más importante de momento fundar talleres de costura, jabón, artesanías que pueden comercializar rápidamente con apoyo de ONGs o del turismo solidario que últimamente invade Gambia.
Nuestra responsabilidad y coincido con Elena Poniatowska (2001) cuando se refiere al trabajo que muchas mujeres, investigadoras, académicas, o voluntarias hacen en las comunidades, es entender que una cosa es alinearse con los pobres y los indígenas desposeídos y otra ahondar en su propia visión del mundo, entender su construcción del yo y los otros, su manera de percibir el cuerpo y la reproducción. Se llega a un tipo muy diferente de comprensión cuando somos capaces de respetar y de entender sus referencias simbólicas en conexión con su vida cotidiana y religiosa. Se trata de dos momentos del compromiso y de dos niveles de la comprensión. Se puede tener lo uno sin lo otro.

Muchas veces, las mujeres que trabajan con mujeres indígenas pueden ser colocadas en alguno de los lugares dentro de un continum que presta atención sólo a las injusticias materiales y a las opresiones de clase y, por otra parte, hay que esforzarse por entender el universo simbólico, religioso y cosmológico en el que esas mujeres tienen un lugar. De lo contrario se corre el riesgo de actuar como "neocolonialistas" o resultar unas intrusas. Si se empieza por forzar un cambio sin respetar sus propios procesos, acaba haciéndose necesario cambiarlas para adaptarlas a las propias concepciones de lo que es la libertad, la justicia y los derechos (Poniatowska, 2001).

El cruzamiento informativo entre lo que relatan y retratan hace evidente que como muchas personas no sabemos qué depara el futuro, no alcanzamos a entender y menos a verbalizar los cambios que acontecen a nuestro alrededor, sin embargo, si estamos conscientes que 
existen otras realidades, quizá mejores o peores, depende desde donde se enfoque, se trata de pensamientos que alimenta la imaginación de un mundo que se construyen a través de ecos que llegan por conversaciones o experiencias de alguien que vive en otra parte, o bien que imaginas cuando ves un recorte de periódico, una película o una telenovela.

El caso de las mujeres gambianas no es diferente, ellas son conscientes de las transformaciones que ha sufrido su país, como lo reconoce Sammeh Jatta, mujer de 70 años, madre de cinco hijos y quien todavía a esa edad va al río a recoger ostras. "Nunca fui a la escuela; sin embargo, yo sabía que mi hija tenía que estudiar con los tubaps (hombre o mujer blanca), porque sólo así le podía ofrecer un mundo diferente al mío, en donde la guerra, las constantes ausencias y las interminables crisis económicas son pan de todos los días".

Las palabras de Sammeh permiten comprender mejor la teoría. Se percibe con claridad cómo a través de sus vivencias y de cada momento histórico político, social y cultural por el que ha atravesado su país, se ha reinventando a sí misma. Es justamente aquí en donde se vislumbran los estragos de un mundo global y de un diálogo monologado.
Quizá alguien pudiera batirse en un sinfín de teorías y analizar las historias desde diferentes posturas y corrientes; sin embargo, son las "sin voz" quienes descubrieron que efectivamente tienen historias que contar.

No se puede entender ningún movimiento sin la recuperación de esas historias; la decolonización empieza con este rescate. La ayuda internacional debe insertarse en países como Gambia, a partir de su cosmovisión de la vida y la forma en que se apropia de los ecos de la poscolonialidad para construir en su diferencia, a fin de cuentas, son los africanos los poseedores de un juego de historias únicas.

Queda de manifiesto que investigaciones apoyadas en los discursos artísticos identifican con mayor claridad, qué pasa con el empoderamiento, las tradiciones, la reconstrucción de su contexto y un sinfín de recovecos solo visibles a través de imágenes, es la reactualización de estudios artísticos que nos permite enfocar culturas que poco a poco, a su paso y a su tiempo se reconstruyen a través de la palabra, el testimonio, las creaciones en medio de un correr vertiginoso de la modernidad tecnológica. 


\section{Referencias}

Algora Weber, Ma. Dolores. (2003). La Historia Contemporánea en África y sus efectos sobre la mujer en la sociedad subsahariana. Cuadernos de Historia Contemporánea 179 -2003, núm. extraordinario 179-190.

Batliwala, Srilatha. (1994). The meaning of women's empowerment: New concepts from action. In Gita Sen, Adrienne Germain y Lincoln C. Chen (eds.). Population Policies reconsidered: health, empowerment and rights. Boston. MD Harvard University Press.

Corona, Sarah. (2007) Entre voces... Fragmentos de educación "entrecultural". México. Ed. Universidad de Guadalajara.

Ewald, Wendy (1999). Secret Games: Collaborative Works with Children 1969-1999, 325. Ed. Universidad Pennsylvania.

Guerrero, Patricio. (2002) La cultura, estrategias, conceptuales para entender la identidad, la diversidad, la alteridad y la diferencia. Ediciones Abya Yala, Quito, Ecuador.

Herrero, José (2002). ¿Qué es cultura? Derechos reservados (C) 2002, José Herrero. http://pnglanguages.org/training/capacitar/antro/cultura.pdf [tomado del internet marzo del 2010].

Jabardo Velasco, M. (2005). Migraciones y género. Cuando el continente africano se hace pequeño. Revista española de Desarrollo y cooperación, (16), 81-97. http://xenero. webs.uvigo.es/profesorado/iria_vazquez/continente.pdf [última visualización 14 de junio 2014].

Juanola, R. \& Calbó, M. (2004). Hacia modelos holísticos en educación artística. Girona, Universidad de Girona.

Kabeer, Naila. (1998). Realidades trastocadas. Las jerarquías de género en el desarrollo del pensamiento. Ed. Paidós. México.

Lacan, J. (1995). Los cuatro conceptos fundamentales del psicoanálisis 1964 (Seminario 11), Buenos Aires, Paidós, 1995, pp. 102-103.

Lagarde, Marcela (1996). Femenismo, Género y Desarrollo Humano. Ed. Horas y horas. Madrid. 
León, Magdalena. (2001). El empoderamiento de las mujeres: Encuentro del primer y tercer mundo en los estudios de género. La ventana No. 13. Ed. Universidad de Guadalajara.

López Méndez, Irene en Carballo de la Riva, Marta. (2006). Género y desarrollo. El camino hacia la equidad. Madrid. Ed. Catarata e Instituto Universitario de Desarrollo y Cooperación.

Marín, R. (2000): "Didáctica de la expresión plástica o educación artística".- En: Rico, L. \& Madrid, D.(eds.), Fundamentos didácticos de las áreas curriculares.-Madrid, Síntesis. 153-207

Martínez, Corona Beatriz. 2000. Género, empoderamiento y sustentabilidad: una experiencia artesanal de mujeres indígenas. Serie PEMSA2 GIMTRAP. México

Moraña, Mabel. (2014) El boom del subalterno. [Versión electrónica] http://www. perio.unlp.edu.ar/catedras/system/files/morana._el_boom_de_lo_subalterno.pdf. Última visualización 06/04/2014. (última visualización 14 de septiembre de 2014).

Obioma Nnaemeka (2005) Conferencias Internacionales como Escenarios para la Lucha Feminista Transnacional: El caso de la Primera Conferencia Internacional sobre las Mujeres de África y de la Diáspora Africanal.

Oyewùmí, Oyèrónké (2012). "Visualizing the Body. Western Theories and African Subjects", in Oyèrónké Oyewùmí (org.), African Gender Studies. A Reader. New York: Palgrave, 137-151.

Ponaitowska, Elena.(2001). Perfil de La Jornada, 13 de marzo, 2001, II

Sipi, Remei (2005). África subsahariana y sus mujeres. Revista Pueblos. No. 11 pp. 50 y 51. Cataluña. 